\title{
Resistencia generalizada a hormonas tiroideas de carácter familiar
}

\author{
José M López M, Marcela Jiménez M, Carmen Campino Ja. \\ Familial generalized thyroid hormone \\ resistance. Report of one case
}

Thyroid hormone resistance is a rare autosomal dominant disease associated, in more than $90 \%$ of cases, to mutations in the beta thyroid hormone receptor. We report a 23 years old male that consulted for a psychiatric condition. Clinically, the patient was euthyroid in spite of high total and free T4 and T3 concentrations, while TSH remained normal. Also, TSH showed a five fold increase under TRH stimulation. The mother and one of his brothers had the same pattern of abnormal serum thyroid hormones. We discuss the diagnostic considerations and the protocol to study this rare pathology (Rev Méd Chile 2004; 132: 1096-9). (Key Words: Receptors, thyroid hormone; Thyroid hormones; Thyroid hormone resistance; Thyronines; Thyroxine)

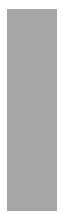

\author{
Recibido el 18 de marzo, 2004. Aceptado el 6 de julio, 2004. \\ Este trabajo fue parcialmente financiado por el Departamento de Endocrinología, Facultad \\ de Medicina, Pontificia Universidad Católica de Chile. \\ Departamento de Endocrinología, Facultad de Medicina, Pontificia Universidad Católica de \\ Chile. \\ aBioquímica
}

L a resistencia a las hormonas tiroideas (RHT), es una entidad heterogénea. Implica disminución de la respuesta de los órganos blanco a las hormonas tiroideas, a pesar que ellas alcancen concentraciones muy elevadas ${ }^{1}$. El nivel metabólico expresará la magnitud de la resistencia de los órganos y cuán hiporreactivos son los tirocitos. Cuando la resistencia compromete equiparadamente a la hipófisis y la periferia, habrá incremento de T4 y T3, con TSH no suprimida o incluso alta y eutiroidismo general ${ }^{2}$. Si la resistencia es más acentuada en la hipófisis habrá TSH, T4 y T3

Correspondencia a: Dr. José M López M. Lira 85-5 piso, Santiago - Chile. Fax: 02-6385675. E mail: jmlopez@med.puc.cl elevadas, con hipertiroidismo. La resistencia extrema periférica, que no logre ser compensada por el aumento de T4 y T3, debiera derivar en hipotiroidismo. La RHT es poco frecuente (incidencia de 1:50.000 nacidos vivos) ${ }^{1}$ y su diagnóstico, en general, es hecho en la infancia.

Presentamos el caso de un adulto con resistencia global a las hormonas tiroideas; el diagnóstico del caso permitió detectar otros dos miembros comprometidos de la familia.

La presente comunicación está enfocada a discutir los elementos substanciales de la enfermedad, la cual no se consigna en la literatura nacional, y a proponer un esquema de estudio cuando existe sospecha clínica de ella. 
Tabla 1. Exámenes de laboratorio del caso índice

\begin{tabular}{|lcccc|}
\hline Parámetros & Valores de referencia & $30 / 07 / 03$ & $19 / 08 / 03$ & $30 / 09 / 03$ \\
\hline T3/T3L $(\mathrm{ng} / \mathrm{dl} / \mathrm{pg} / \mathrm{dl})$ & $75-180 / 230-420$ & & $216 / \mathrm{nr}$ & $276 / 907$ \\
T4/T4L $(\mu \mathrm{g} / \mathrm{dl} / \mathrm{ng} / \mathrm{dl})$ & $4-12 / 0,9-1,9$ & $\mathrm{nr} / 4,06$ & $14,7 / 3,3$ & $14 / 3,4$ \\
TSH $(\mu \mathrm{UI} / \mathrm{ml})$ & $0,4-4,3$ & & 2,1 & \\
TBG $(\mu \mathrm{g} / \mathrm{ml})$ & $0-60$ & & & 15,0 \\
Ac antiperoxidasa (UI/ml) & $<12$ & 19 & & \\
Ac antitiroglobulina (UI/ml) & $<34$ & 28 & & \\
Ac antirreceptor de TSH (\%) & $<11$ & nd & 16 & Normal \\
Captación de I31 a las 24 h (\%) & & & & \\
Electroforesis de proteínas & & & & \\
\hline
\end{tabular}

nd: no detectable; nr: no realizado.

\section{CASO CLÍNICO}

Hombre de 23 años de edad, estudiante universitario, quién consultó a un siquiatra por agresividad y trastorno del ánimo. Las pruebas tiroideas iniciales resultaron anómalas (T4: 15,2 $\mu \mathrm{g} / \mathrm{dl}$; TSH: 2,0 $\mu \mathrm{U} / \mathrm{mL}$ ) lo que motivó la interconsulta. La anamnesis no detectó elementos sospechosos de disfunción tiroidea, mientras el peso corporal era estable. No relataba usar bloquedores beta-adrenérgicos, o drogas que afecten la síntesis o el transporte de las hormonas tiroideas. Su audición era normal.

Los antecedentes eran: ictericia de recién nacido con síndrome convulsivo y recambio sanguíneo y haber tenido algunos roedores como mascotas en la infancia. Su madre fue tiroidectomizada parcialmente por un nódulo benigno. Se mantiene con $100 \mu \mathrm{g} /$ día de L-tiroxina.

El examen físico constató el buen estado general, con pulso regular de $70 \mathrm{x}$ min y presión arterial normal. La condición clínica era de eutimidismo. El tiroides estaba crecido difusamente, simétrico y de consistencia normal. Los exámenes concordaron con el patrón inicial: T4: 14,7 $\mu \mathrm{g} / \mathrm{dl}$; T3: $216 \mathrm{ng} / \mathrm{dl}$; TSH: 2,06 $\mu \mathrm{IU} / \mathrm{ml}$. La ecografía tiroidea corroboró el crecimiento difuso de ambos lóbulos, con ecogenicidad normal, sin aumento de circulación. El istmo medía $5 \mathrm{~mm}$. Las concentraciones de las hormonas tiroideas basales, de sus transportadores, y de TSH se muestran en la Tabla 1. La respuesta de TSH y prolactina a los 30 y 60 min, post TRH ( $200 \mu \mathrm{g} \mathrm{ev})$ se presenta en la Figura 1. Los anticuerpos específicos anti T4 fueron negativos en el caso índice y sus dos hermanos. La imagen de región selar en tomografía axial computada (TAC) fue enteramente normal.

Las concentraciones de las hormonas tiroideas correspondientes a sus padres y hermanos se muestran en la Tabla 2, encontrándose en la madre y uno de los hermanos un patrón hormonal similar al del caso índice.

\section{DisCUSIÓN}

La RHT es una enfermedad hereditaria, caracterizada por disminución, en grado variable, de la respuesta a las hormonas tiroideas por parte de sus órganos blancos ${ }^{2}$. El patrón clásico de sospe-

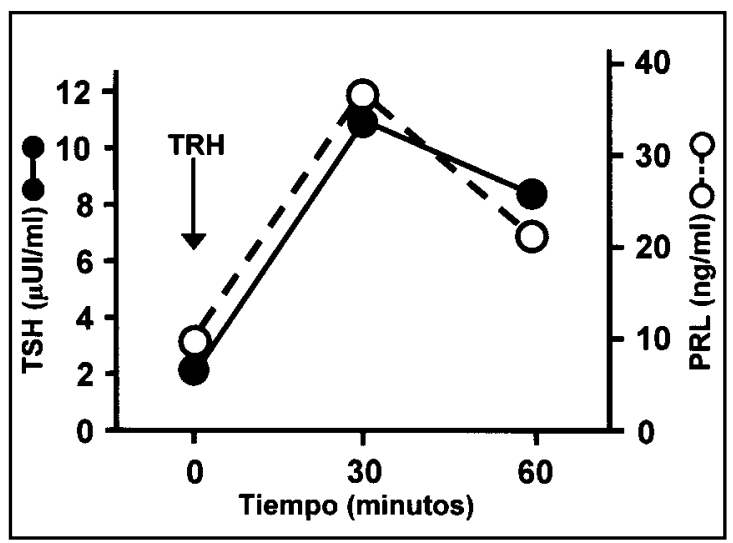

FIGURA 1. Respuesta de TSH y prolactina a los $0,+30 \mathrm{y}$ +60 min, post TRH (200 $\mu \mathrm{g} \mathrm{ev})$. 
Tabla 2. Estudio familiar

\begin{tabular}{|lcccccc|}
\hline Examen & $\begin{array}{c}\text { Valores de } \\
\text { referencia }\end{array}$ & $\begin{array}{c}\text { Caso } \\
\text { índice }\end{array}$ & Padre & Madre & Hno. & Hna. \\
\hline T4 $(\mu \mathrm{g} / \mathrm{dl})$ & $4-12$ & 14,6 & 6,6 & 15,2 & 15,9 & 5,8 \\
T4L $(\mu \mathrm{g} / \mathrm{dl})$ & $0,9-1,9$ & 3,4 & 1,2 & 3,6 & 2,7 & 1,2 \\
T3 $(\mathrm{ng} / \mathrm{dl})$ & $75-180$ & 276 & 139 & 182 & 270 & 118 \\
T3L $(\mathrm{pg} / \mathrm{dl})$ & $230-420$ & 907 & 342 & 573 & 767 & 320 \\
TSH $(\mu \mathrm{UI} / \mathrm{ml})$ & $0,4-4,3$ & 2,0 & 0,67 & 0,94 & 0,76 & 0,9 \\
\hline
\end{tabular}

cha es elevación de T4 y T3 libres con TSH normal o ligeramente elevada.

T4 y T3, en sus formas libres, entran a las células por difusión. La T3, es transferida al núcleo $\mathrm{y}$ se une a receptores presentes como dímeros unidos a sequencias específicas de ADN, ubicadas en la región promotora de los genes que responden a las hormonas tiroideas ${ }^{1,2}$.

Existen dos tipos de receptores para hormonas tiroideas, alfa y beta, codificados en genes de los cromosomas 17 y 3 , respectivamente ${ }^{3}$. Los receptores se asemejan en su estructura y secuencia; el splicing de cada uno de ellos generará dos formas por cada receptor: beta 1 y 2; alfa 1 y 2 . Sólo los tres primeros actúan como receptores para T3. Los dímeros de los receptores que no ligan a T3, se unen a otros elementos de la expresión de genes que son positivamente regulados por T3. La T3, al unirse a su receptor, genera un cambio conformacional liberando proteínas correpresoras de la expresión, disociando los dímeros y formando heterodímeros entre el receptor hormonal ya separado y receptores retinoideos X. Este heterodímero se une a proteínas coactivadoras que favorecen la expresión del gen y la síntesis de proteínas específicas ${ }^{2}$.

La RTH es debida a mutaciones del receptor beta de las hormonas tiroideas, de transmisión autosómica dominante, sin predominancia por sexo. A la fecha, se han reconocido alrededor de 600 casos con RHT, de 200 familias con RTH, y se han descrito más de cien mutaciones distintas del receptor beta ${ }^{1}$. En las familias afectadas se encontró más de una mutación en $66 \%$ y mutaciones de novo (otros familiares no comprometidos) en 15\%; en $10 \%$ no se encontró mutación ${ }^{2,4}$. Se conoce una familia cuyos individuos tienen deleción completa del gen receptor beta y que, contrariamente al resto de la experiencia, se transmitía de manera recesiva ${ }^{3}$. En los sujetos heterozigotos de esta familia, el alelo sano era capaz de mantener función normal ${ }^{2}$.

Clínicamente es de ayuda tratar de definir dónde la resistencia se expresa más notoriamente, a pesar que ello no tiene un correlato genético que lo avale ${ }^{1}$. Cuando los tirotropos son hiporreactivos, la hipófisis detecta erróneamente un déficit de hormonas tiroideas y aumenta TSH hasta que el nivel de hormonas tiroideas alcance un equilibrio y la TSH se mantenga moderamente alta o normal. La presencia de eutiroidismo o hipertiroidismo dependerá del grado de compromiso de los tejidos periféricos, de modo que si éste es leve habrá hipermetabolismo (forma central de RHT), o si éste es marcado, se mantendrá el eutiroidismo (forma generalizada).

En nuestro caso, la presentación fue la habitual, T4 y T3 libres elevadas en un contexto de eutirodismo, y con TSH no suprimida. La calidad biológica de TSH está avalada porque, en ausencia de otras patologías, creció el tiroides, la captación de yodo 131 era normal y la síntesis de hormonas tiroideas estaba claramente aumentada.

Dado que la causa más frecuente de hipertiroxinemia eutiroidea es por aumento de la TBG, es importante certificar la indemnidad de los transportadores de hormonas tiroideas, frecuente en mujeres dado lo habitual del uso de estrógenos.

En nuestro caso, no se encontró ninguna droga que pudiese modificar la TBG. Además, T4 y T3 libres también estaban elevadas y TBG era normal. La albuminemia y la electroforesis de proteínas fueron normales. 
Entre las causas metodológicas que puedan interferir en la correcta determinación de T4 está la presencia de autoanticuerpos anti T4. Dependiendo del método con que se mida T4, los autoanticuerpos anti T4 pueden sobre o subestimar la concentración real de T4.

En esta familia, la presencia de anticuerpos anti T4 quedó descartada, ya que al incubar el suero con T4 marcada con $\mathrm{I}^{125}$ y luego precipitar con antigama globulina humana, no se encontró radiactividad en el precipitado indicando ausencia de complejo $\mathrm{I}^{125}$-T4-anticuerpo anti T4.

Con las consideraciones precedentes, si hay duda respecto a si el paciente es eu o hipertiroideo, deben emplearse mediciones indirectas del estado metabólico, como SHBG (sube en el hipertiroidismo), perfil lipídico, calorimetría y evaluación del gasto cardíaco ${ }^{2}$.

La presencia de eutiroidismo descarta un tumor hipofisiario productor de TSH, el que aunque comparte el patrón de T4 y T3 totales y libres altas, TSH normal o elevada, presenta hipertiroidismo. Concordante con el eutiroidismo de nuestro paciente, la TAC de silla turca certificó una hipófisis normal.

\section{REFERENCIAS}

1. ReFETOFF S. Chapter 16D: The syndromes of resistance to thyroid hormone. En: The Thyroid and its Diseases. 2002. Disponible en: www.thyroidmanager.org/

2. Refetoff S, Weiss RE, Usala SJ. The syndrome of resistance to thyroid hormone. Endoc Rev 1993; 14: 348-99.

3. Ono S, Schwartz ID, Muelere OT, Root AW, USALA SJ, BERCU BB. Homozygosity for dominant negative thyroid hormone receptor gene responsible for generalized resistance to thyroid
También debe investigarse la respuesta de TSH a TRH, que en un individuo normal, ante los elevados niveles de hormonas tiroideas libres debiera abolir el ascenso de TSH. La Figura 1 muestra, sin embargo, una respuesta normal a TRH (TSH subió 5 veces), evidenciando la hiporreactividad de los tirocitos, mientras la respuesta de prolactina fue acorde al estímulo.

Completado así el estudio, quedó configurado el cuadro de resistencia a hormonas tiroideas de carácter familiar, en condición de eutiroidismo.

El caso de la madre, portadora de la enfermedad (Tabla 2), señala dos hechos: que la enfermedad no fue detectada cuando se sometió a tiroidectomía por un nódulo benigno y que la enfermedad se sigue expresando con gran elevación de T4 y T3 libres, a pesar de la disminución de masa tiroidea.

El tratamiento de la RHT dependerá del nivel de equilibrio alcanzado entre las hormonas tiroideas y TSH; en nuestro caso, el eutiroidismo presente no amerita intervención ${ }^{5,6}$. El seguimiento ecográfico es mandatorio por el mayor riesgo de desarrollar nódulos tiroideos ${ }^{1,2}$ y eventualmente cáncer de tiroides por el estímulo permanente de TSH.

hormone. J Clin Endocrinol Metab 1991; 73: 990-4.

4. Asteria C, Rajanayagam O, Cowngwood TN, Persani L, Romol R, Manavola D et al. Prenatal diagnosis of thyroid hormone resistance. J Clin Endocrinol Metab 1999; 84: 405-10.

5. Kunitake JM, Hartman N, Henson L, Lieberman J, Wiwams DE, Wong M et aL. 3,5,3'-Triiodothyroacetic acid therapy for thyroid hormone resistance. J Clin Endocrinol Metab 1989; 69: 461-6.

6. WeISS RE, ReFEToff S. Treatment of resistance to thyroid hormone-Primum non nocere. J Clin Endocrinol Metab 1999; 84: 401-4. 